\title{
Sensory input and cholinergic agents: Interacting effects on short-term memory in the mouse
}

\author{
JEFFREY S. STRIPLING and HERBERT P. ALPERN \\ Institute for Behavioral Genetics, University of Colorado, Boulder, Colorado 80302
}

\begin{abstract}
The effects of scopolamine, physostigmine, and sensory stimulation on short-term memory (STM) were assessed in male C57BL/6 mice using a successive-reversal avoidance paradigm. Scopolamine disrupted STM at a 5-min delay interval, but STM was significantly improved under scopolamine when sensory stimulation during this delay interval was reduced below normal levels. The level of sensory stimulation during the 5-min delay interval had no effect on STM in animals treated with saline or physostigmine. Moreover, unusually poor control performance apparently prevented detection of disruptive or facilitative effects of physostigmine at 5 and $20 \mathrm{~min}$, respectively. It was concluded that the interaction between sensory stimulation and scopolamine might reflect cholinergic involvement in sensory processing.
\end{abstract}

It is well known that for a period of time following a learning event, memory of that event is susceptible to disruption by a variety of amnesic agents such as electroconvulsive shock (ECS) (McGaugh \& Herz, 1972) as well as to facilitation by certain drugs and other treatments (Essman, 1971). One variable that has been studied in this respect is sensory input. Consolidation theory postulates an important role for "neural rehearsal" in the formation of memory (Glickman, 1961; Hebb, 1949) and, consequently, it has been postulated that a high level of sensory stimulation should be disruptive of memory formation due to the creation of competing neural activity and the prevention of neural rehearsal (Calhoun, 1966). Experimental tests have failed to verify this (Calhoun, 1966; Calhoun \& Murphy, 1966), although an elimination of drugproduced facilitation of memory formation has been observed (Calhoun, 1966). In addition, several studies have found facilitation of memory formation when animals were protected from normal levels of sensory stimulation (Calhoun \& Murphy, 1966; Thompson, 1957; Thompson \& Bryant, 1955).

All of the preceding experiments studied the effects of sensory stimulation on long-term memory (LTM); that is, the learning paradigms which were used produced strong retention which lasted for a period of days or longer. Short-term memory (STM) may well be more sensitive to sensory input because of its transitory nature and its sensitivity to the presence

This report is based on a portion of the doctoral dissertation submitted by the first author to the Department of Psychology at the University of Colorado. The research was supported by NIMH Grant MH 11167. The authors wish to thank Rachel Cohen for her assistance in training the animals. J. S. Stripling is now at the Behavioral Neuropharmacology Section, Department of Psychiatry, Box 3838, Duke University Medical Center, Durham, North Carolina 27710. Requests for reprints should be sent to Herbert P. Alpern, Department of Psychology, University of Colorado, Boulder, Colorado 80302. or absence of rehearsal and interference (Deese \& Hulse, 1967). Recently, Alpern and Marriott (1972a) developed a method for the direct measurement of STM in the mouse using a successive-reversal learning set paradigm. As measured by this method, STM in a variety of strains of mice reliably falls to chance levels within $30 \mathrm{~min}$ (Alpern \& Marriott, 1972b, 1973; Marriott, 1974; Stripling, 1974). One purpose of the present experiment was to assess the effects of different levels of sensory stimulation on STM as measured by this paradigm.

An important characteristic of this paradigm is that it permits a relatively clear-cut distinction to be made between the effects of drugs on STM and on performance. Utilizing this advantage, experiments have shown STM to be strongly influenced by drugs affecting cholinergic transmission but not by drugs affecting adrenergic transmission (Alpern \& Marriott, 1973; Marriott, 1974; Marriott \& Alpern, 1975). Specifically, the cholinolytic agent scopolamine disrupts STM and the cholinesterase inhibitor physostigmine facilitates it (Alpern \& Marriott, 1973). Thus, the expression of STM in this task appears related to the strength of cholinergic transmission.

It has been proposed that there is a cholinergic mechanism involved in the control of sensory input (Carlton, 1968; Warburton, 1972). If sensory input is disruptive of STM, it may be that cholinergic agents affect STM by altering the effects of sensory stimulation normally present in the environment. If so, there should be an interaction between the effects of cholinergic agents and sensory stimulation on STM. A second purpose of the present experiment was to study the possibility of such an interaction.

In order to study the effect of sensory stimulation on STM, three conditions were administered: normal, in which the subjects were exposed to the sensory stimuli normally present in the laboratory; protected, in which sensory input was reduced as much as possible; and stimulated, in which sensory input was increased beyond that normally present. Cholinergic transmission 
was manipulated by administering scopolamine and physostigmine. The effect of scopolamine was assessed at a time (5-min delay interval) when STM is normally quite strong, and the effect of physostigmine was assessed at a 20-min delay interval. At this latter delay STM is characteristically weak. Moreover, the effect of physostigmine on STM was measured at a 5-min delay interval in order to determine whether an increase in cholinergic activity at a time when STM is strong might produce disruption of STM, in contrast to the facilitating effect it produces when STM is weak (Alpern \& Marriott, 1973).

\section{METHOD}

\section{Subjects}

The subjects were 61 male C57BL/6IBG inbred mice obtained from the Institute for Behavioral Genetics at the University of Colorado. They were housed six to a cage and were maintained on a 12 -h-on/12-h-off light cycle. Training began at 76-107 days of age.

\section{Apparatus}

A T-maze was used as the training apparatus. Its walls were constructed of $1 / 4$-in. white Plexiglas, the floor of $3 / 32$-in. stainless steel rods spaced $4.1 \mathrm{~mm}$ apart, and the top of $1 / 8$-in. clear Plexiglas. The dimensions of the start alley were $291 / 2 \times 4 \times 9 \mathrm{~cm}$; each choice arm measured $21 \times 4 \times 9 \mathrm{~cm}$. Aluminum doors which could be raised from below the grid floor were located at the entrance of the start alley and at the end of each choice arm. The interior walls of the choice arms were covered with aluminum plates. Both these and the grid floor were electrified via a shock scrambler and an alternating-current shock source which delivered $2 \mathrm{~mA}$ to a $10 \mathrm{~K}-\mathrm{ohm}$ resistance. A Sonalert tone generator emitting a $4000-\mathrm{Hz} 105-\mathrm{dB}$ tone was located directly above the choice point of the maze.

Two insulated freezer chests, designated as the protected and stimulated chambers, were used to manipulate sensory input. Each chamber could accommodate three animal holding cages at one time. The protected chamber contained a $71 / 2-\mathrm{W}$ white incandescent light bulb which burned continuously. The stimulated chamber contained a $10-\mathrm{W}$ clear incandescent light bulb which flashed off and on approximately 100 times a minute. In addition, the stimulated chamber contained three 2-in. 8-oh.n speakers, one mounted directly above each cage position. During the experiment, a tape recording of white noise generated by a Grason-Stadler Model 901B noise generator was played through these speakers. The recording was not continuous but consisted of three different durations of white noise $\left(1 \frac{1}{2}, 3 \frac{1}{2}\right.$, and $\left.5 \frac{1}{2} \mathrm{sec}\right)$ combined at random with two different durations of silence $\left(2\right.$ and $\left.3^{1 / 2} \mathrm{sec}\right)$. The resulting unpredictability was intended to reduce habituation of the subjects to the stimulus. The frequency spectrum of the white noise was measured within the stimulated chamber using a Tektronix 564 storage oscilloscope with a 3L5 spectrum analyzer and a Bruel and Kjaer Type 4135/36 microphone. The spectrum was approximately normally distributed, with a maximum of $10 \mathrm{Khz}$ and falling to one-half amplitude at 7 and $13 \mathrm{Khz}$. The high frequency of this stimulus was compatible with the auditory characteristics of the mouse, which is maximally sensitive to frequencies between 10 and $20 \mathrm{Khz}$ and is relatively insensitive to frequencies below $5 \mathrm{Khz}$ (Green, 1966, p. 617).

Sound amplitude in the various parts of the experimental environment was measured with a General Radio Company Type 1565-A sound -level meter with an A weighting. The background noise in the experimental room (due primarily to the blower circulating air through the maze) was $54 \mathrm{~dB}$ as measured within a holding cage on its storage shelf (the normal condition). The Sonalert tone generator mounted within the T-maze produced an $80-\mathrm{dB}$ tone within a holding cage. Within the stimulated and protected chambers, this was reduced to $65 \mathrm{~dB}$. The white noise being played through the speakers in the stimulated chamber measured $85 \mathrm{~dB}$ within this chamber, $47 \mathrm{~dB}$ in a holding cage in the room, and was undetectable in the protected chamber.

\section{Procedure}

Throughout the experiment, a trial consisted of the following procedure. The animal was placed in the start alley of the maze and the door raised behind it. Two seconds later the tone generator sounded for $.5 \mathrm{sec}$, serving as a warning signal. At the termination of the tone, the floor of the start alley and the walls and floor of the incorrect choice arm were electrified. If the animal entered and remained in the correct choice arm until the termination of the tone, the door in that choice arm was lowered and the animal was allowed to exit into a small stainless steel holding cage. If the animal failed to leave the start alley before the onset of shock and/or chose the incorrect arm of the maze, the animal was allowed to escape into the correct arm and exit into the holding cage. Both avoidance errors (failure to make a choice before the onset of shock) and choice errors (entrance into the incorrect arm of the maze) were recorded. Thus, an animal could receive one of four possible scores on a trial: (a) correct avoidance-the subject was in the correct choice arm at the termination of the tone; (b) incorrect avoidance-the subject was in the incorrect choice arm at the termination of the tone; (c) correct escape-the subject was in the start alley at the termination of the tone and entered the correct choice arm upon leaving the start alley; and (d) incorrect escape-the subject was in the start alley at the termination of the tone and entered the incorrect choice arm upon leaving the start alley. Each animal was housed in an individual holding cage for the duration of each day's testing.

In the first phase of the experiment, the animals were trained to develop a successive-reversal learning set. Every day each animal was trained to choose either the right or left arm of the maze using a 5-min intertrial interval. Daily testing was terminated when a criterion of five correct avoidances out of six trials was met, with no errors on the last two trials, or until a maximum of 40 trials was reached. At this point, training for the day was terminated. Each day the position discrimination was reversed from that learned on the previous day. The only cue signaling this reversal was the presence of footshock in the incorrect choice arm. Animals trained in this fashion reliably entered the previously correct choice arm on the first trial of each day and received a footshock. Consequently, this trial, called the sign trial, served as a signal to the animal to reverse its behavior from that learned the previous day. As training progressed, animals learned to reverse their behavior very efficiently on the basis of information conveyed on the sign trial. Every day every animal was scored by the number of errors committed in attaining the position preference, excluding the sign trial; any response other than a correct avoidance was counted as an error. The criterion for acquisition of the successive-reversal learning set for each animal was one error or less within a 3 -day period. Animals requiring more than 28 days of training to acquire the learning set were discarded from the experiment. As each animal attained the learning set criterion, it was advanced to the delayed-response phase of the experiment.

The procedure used each day during delayed-response testing was as follows: As in the training phase, each animal was trained to a position preference each day which was reversed from day to day. The first trial of each day (the sign trial) signaled a reversal of the position discrimination learned the previous day. The second trial of the day, called the test trial, was separated 
from the sign trial by the delay interval to be used on that day. The test trial was used to assess retention of the sign trial. Subsequently, using a 5-min intertrial interval, the animal was trained to the same criterion of position preference used daily during learning set acquisition.

The effects of sensory input and cholinergic agents on STM were assessed in this phase of the experiment. The effects of scopolamine hydrobromide on STM were assessed at a delay interval of $5 \mathrm{~min}$; the effects of physostigmine salicylate on STM were assessed at both $5 \mathrm{~min}$ and $20 \mathrm{~min}$. For scopolamine the following dosages were used: $.0 \mathrm{mg} / \mathrm{kg}$ (vehicle only), $.5 \mathrm{mg} / \mathrm{kg}$, and $2.0 \mathrm{mg} / \mathrm{kg}$; for physostigmine the dosages were $.0 \mathrm{mg} / \mathrm{kg}$ (vehicle only), $.5 \mathrm{mg} / \mathrm{kg}$, and $.20 \mathrm{mg} / \mathrm{kg}$. The effect of each dosage was assessed under three stimulus conditions: normal, protected, and stimulated. This resulted in 27 treatment conditions which were administered to each animal in a repeated measures design. Animals were tested for 9 days under each of three drug-interval conditions: scopolamine $(5 \mathrm{~min})$, physostigmine $(5 \mathrm{~min})$, and physostigmine $(20 \mathrm{~min})$. A complete twofactorial design (dosage by stimulus condition) was run under each of the three conditions. The order of presentation of the levels of each variable was counterbalanced across animals by means of a Latin square.

All drug solutions were prepared in physiological saline. Injections were given $30 \mathrm{~min}$ before the sign trial for each animal. Following the sign trial, the animals were treated as follows according to stimulus condition. Animals in the normal condition were returned to their holding cages and placed upon a storage shelf in the experimental room for the duration of the delay interval. Following the test trial and all subsequent trials, they were also returned to this shelf. This is the procedure that has been followed in previous experiments using this paradigm. Animals in the protected and stimulated conditions were returned to their holding cages following the sign trial and placed in the appropriate chamber within $10 \mathrm{sec}$ of exiting from the T-maze. They remained in the stimulus chamber for the duration of the delay interval; they were then removed and administered the test trial within $10 \mathrm{sec}$ of removal. Following the test trial, they were treated as were animals in the normal condition.

The day following the attainment of the learning set criterion served as a control day for each animal to permit adjustment to experimental conditions. The animal was injected with saline and was trained in the normal condition at the delay interval which was appropriate for the first drug-interval condition to be tested. This was followed by 9 days of testing under that druginterval condition. The second and third drug-interval conditions followed. A control day similar to that of the first day was inserted between any two drug-interval conditions for which the delay interval differed, permitting adjustment to the change. The data for all such control days were not included in the experimental analyses.

During the delayed-response phase of the experiment, the animals demonstrated a significant preference for the incorrect choice arm on the sign trial. Although this response conveys as much information concerning which alley is correct as does receiving footshock in the incorrect alley, it is doubtful that it has the salience of the latter response and, therefore, may produce weaker retention of the sign trial (STM). In addition, a correct response on the sign trial may indicate that the animal has not adequately retained the previous day's position preference and is performing at random. For these reasons, the data for all days on which an animal made a correct choice on the sign trial were discarded and the experimental conditions for those days were readministered to the animal. As before, a control day was introduced whenever the delay interval was changed. Each animal was retired from the experiment when the recollection of its discarded data was completed. Animals requiring more than 70 days to complete the experiment were discarded.

\section{RESULTS}

The 54 animals completing the experiment required an average of 15.9 days to attain the learning set criterion. Four animals were discarded for failure to attain the learning set criterion within 28 days. Two other animals died from tetanizing electric shock after biting one of the stainless steel bars in the grid floor, and one animal was discarded for failure to complete the experiment within 70 days of training.

The data for each of the three drug-interval conditions were analyzed separately by a two-way analysis of variance with repeated measures on both factors. The results for each of the conditions will be considered in turn.

\section{Scopolamine (5 Min)}

The results for the scopolamine (5-min) condition are given in Table 1. The effect of scopolamine on STM (as measured by correct avoidance on the test trial) was highly significant $(F=15.96, d f=2 / 106$, $\mathrm{p}<.01$ ). Inspection of the data (see Table 1 ) revealed a dose-dependent disruption of STM by scopolamine. Conceivably this effect could have been due to locomotor impairment by scopolamine, which would have prevented the animals from leaving the start alley in time to avoid footshock without impairing their choice behavior. To assess this possibility, the effect of scopolamine on choice behavior (correct avoidances plus correct escapes) was also analyzed. A highly significant effect was again found $(F=10.41, d f=2 / 106, p<.01)$.

No significant effect of stimulus condition on STM was found, either for correct avoidances or for correct choices. In addition, there was no significant interaction of Drug Dosage by Stimulus Condition.

In order to explore further the effects of scopolamine and stimulus condition on STM, an analysis was made of errors to criterion in each treatment condition. This measure consists of all responses other than a correct avoidance made by an animal on all trials following the test trial. Performance on this measure indicates the rapidity with which an animal reached the daily position preference criterion of five correct avoidances in six trials. The maintenance of correct responding from trial to trial depends upon memory, thus errors to criterion reflect the strength of STM; to an undetermined extent, it also reflects LTM and, thus, would not normally be considered as accurate a measure of STM as test trial performance. However, in the present experiment test trial performance was strongly depressed by scopolamine, possibly creating a "ceiling effect" which prevented the detection of additional alterations in STM due to the stimulus condition. The errors to criterion score provides a measure of how quickly STM recovered from the effects of scopolamine, and thus it may allow the detection of differences in STM which were not visible on the test trial. 
Table 1

Effect of Dosage and Stimulus Condition on Test Trial Performance and Errors to Criterion in the Scopolamine (5-Min) Condition

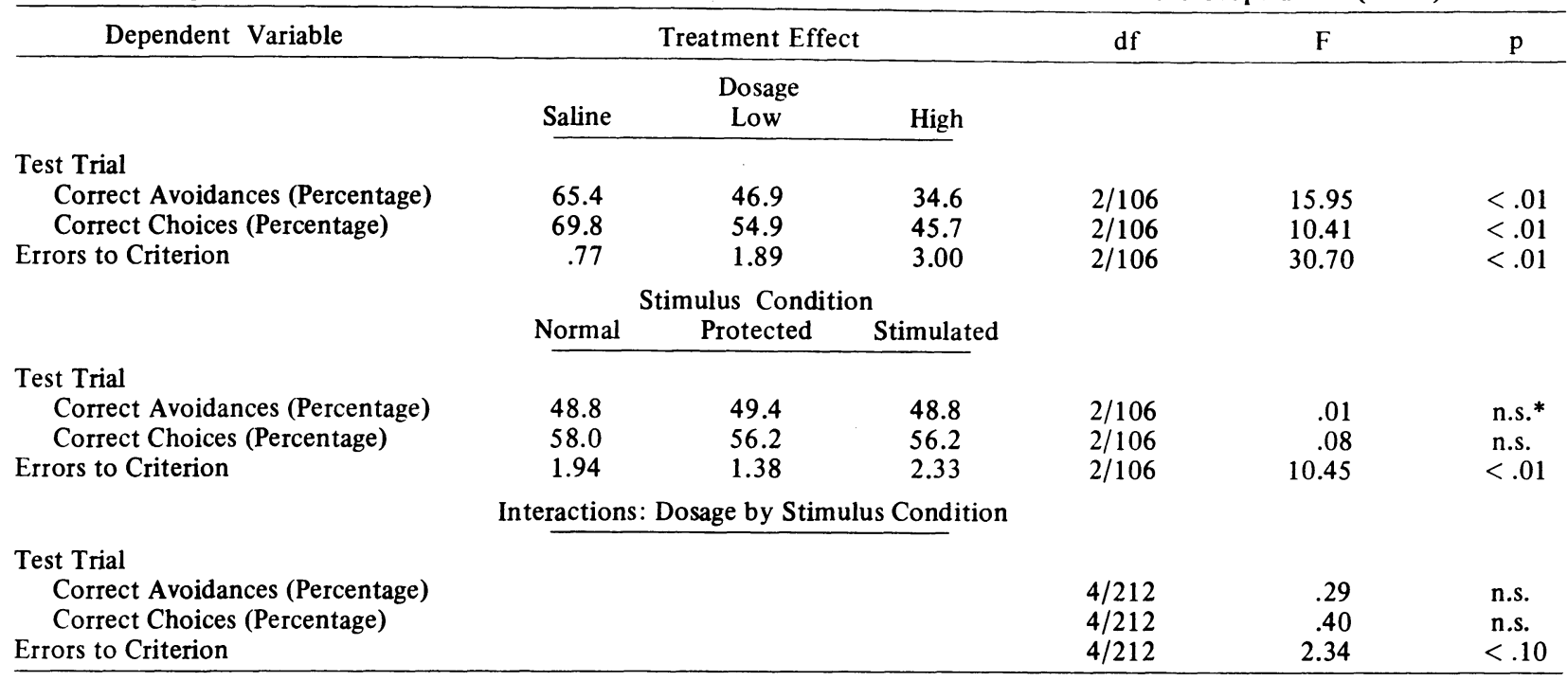

${ }^{*}$.s. $=$ not significant

Both dosage and stimulus condition had a highly significant effect on errors to criterion (dosage: $\mathrm{F}=$ $30.70, \mathrm{df}=2 / 106, \mathrm{p}<.01 ;$ stimulus condition: $\mathrm{F}=$ $10.45, \mathrm{df}=2 / 106, \mathrm{p}<.01$ ). Inspection of the data (see Table 1) revealed a marked dose-dependent disruption of performance by scopolamine. In addition, the stimulus condition effects were in the predicted direction: The protected condition had the least errors and the stimulated condition had the most. Each of these conditions was compared with the normal condition by Sandler's A test (Runyon \& Haber, 1971, p. 210). The protected condition was significantly better than the normal condition $(\mathrm{A}=.118, \mathrm{df}=53, \mathrm{p}<.01$, twotailed), but the stimulated condition was not significantly worse than the normal condition $(\mathrm{A}=.381$, $\mathrm{df}=53, \mathrm{p}>.10$, two-tailed).

In addition to these findings, the interaction of Dosage by Stimulus Condition approached significance $(F=2.34, \mathrm{df}=4 / 212, \mathrm{p}<.10)$. In order to examine any possible interaction, errors to criterion were broken down by dosage and stimulus condition (see Figure 1). Inspection of Figure 1 revealed that the stimulus condition effects appeared confined to the two scopolamine groups. A one-way analysis of variance of the stimulus condition effect within each dosage confirmed this (saline: $\mathrm{F}=.49, \mathrm{df}=2 / 106 ;$ low dose: $\mathrm{F}=4.70, \mathrm{df}=$ $2 / 106, \mathrm{p}<.05 ;$ high dose: $\mathrm{F}=5.71, \mathrm{df}=2 / 106, \mathrm{p}<$ $.01)$. However, even if only performance under the two dosages of scopolamine were analyzed, comparison of the stimulus conditions yielded the same results: The protected condition produced significantly better performance than the normal condition $(\mathrm{A}=.112$, $\mathrm{df}=53, \mathrm{p}<.01$, two-tailed), but performance in the stimulated condition was not significantly worse than in the normal condition $(\mathrm{A}=.457, \mathrm{df}=53, \mathrm{p}>.10$, two-tailed). If only performance under the high dose of scopolamine was considered, the tendency of the stimulated condition to disrupt performance in comparison to the normal condition approached but did not reach significance $(A=.314, \mathrm{df}=53, \mathrm{p}>.10$, twotailed).

Because the effects of scopolamine on STM were quite pronounced, performance on the sign trial was analyzed to determine whether LTM was also affected. Performance on the sign trial reflects retention of the position preference learned the previous day and is dependent upon LTM. The effect of scopolamine on retention of this position preference was analyzed by a one-way analysis of variance with a repeated measure comparing choice behavior on the sign trial for the three dosages. For this analysis all data were used which had been collected before the correct sign trial responses were discarded. No significant effect of scopolamine was found $(\mathrm{F}=.86, \mathrm{df}=2 / 106)$.

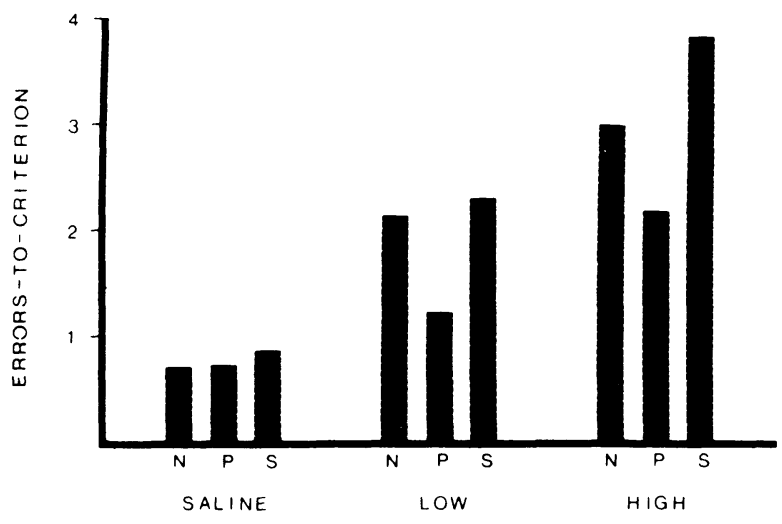

Figure 1. Effect of stimulus condition on errors to criterion within each dosage in the scopolamine (5-min) condition. $\mathbf{N}=$ normal, $\mathbf{P}=$ protected, $\mathrm{S}=$ stimulated. 
Table 2

Effect of Dosage and Stimulus Condition on Test Trial Performance and Errors to Criterion in the Physostigmine (5-Min) Condition

\begin{tabular}{|c|c|c|c|c|c|c|}
\hline Dependent Variable & \multicolumn{3}{|c|}{ Treatment Effect } & df & $\mathbf{F}$ & $\mathrm{p}$ \\
\hline & \multicolumn{3}{|c|}{ Dosage } & & & \\
\hline & Saline & Low & High & & & \\
\hline \multicolumn{7}{|l|}{ Test Trial } \\
\hline Correct Avoidances (Percentage) & 69.8 & 67.9 & 73.5 & $2 / 106$ & .63 & n.s.* \\
\hline Correct Choices (Percentage) & 74.1 & 71.0 & 77.2 & $2 / 106$ & 1.00 & n.s. \\
\hline Errors to Criterion & .74 & .68 & .65 & $2 / 106$ & .22 & n.s. \\
\hline \multicolumn{7}{|c|}{ Stimulus Condition } \\
\hline & Normal & Protecte & Stimulatec & & & \\
\hline Test Trial & & & & & & \\
\hline Correct Avoidances (Percentage) & 68.5 & 71.6 & 71.0 & $2 / 106$ & .22 & n.s. \\
\hline Correct Choices (Percentage) & 72.2 & 73.5 & 76.5 & $2 / 106$ & .46 & n.s. \\
\hline Errors to Criterion & .71 & .66 & .69 & $2 / 106$ & .09 & n.s. \\
\hline \multicolumn{7}{|c|}{ Interactions: Dosage by Stimulus Condition } \\
\hline \multicolumn{7}{|l|}{ Test Trial } \\
\hline Correct Avoidances (Percentage) & & & & $4 / 212$ & .66 & n.s. \\
\hline Correct Choices (Percentage) & & & & $4 / 212$ & .44 & n.s. \\
\hline Errors to Criterion & & & & $4 / 212$ & 1.02 & n.s. \\
\hline
\end{tabular}

${ }^{*}$ n.s. $=$ not significant

In addition, the effect of scopolamine on the formation of LTM was examined. In this analysis two conditions were compared. In both conditions choice behavior on the sign trial was examined for days on which the animal had been injected with saline. In the first condition the animal had been injected the previous day with saline; in the second the high dose of scopolamine had been used. Thus, if the formation of LTM was affected by scopolamine, the second condition should show poorer retention of the previous day's position preference than the first condition. This was not borne out. The first condition performed the previous day's position preference $74.1 \%$ of the time, the second condition $72.2 \%$ of the time. This difference was far short of significance $(A=21.0, d f=53, p>.10)$. In addition to discounting an effect of scopolamine on the formation of LTM, this finding also argues against the presence of any state-dependent effects of scopolamine, since retention in an undrugged state of the previous day's position preference was unaffected by whether the position training occurred in a drugged or undrugged state.

Physostigmine (5 Min) and Physostigmine (20 Min) The results of the physostigmine (5-min) and physostigmine (20-min) conditions are indicated in Tables 2 and 3, respectively. There were no significant effects of either dosage or stimulus condition on any of the three dependent variables in either condition.

Table 3

Effect of Dosage and Stimulus Condition on Test Trial Performance and Errors to Criterion in the Physostigmine (20-min) Condition

\begin{tabular}{|c|c|c|c|c|c|c|}
\hline Dependent Variable & \multicolumn{3}{|c|}{ Treatment Effect } & df & $\mathrm{F}$ & $\mathrm{p}$ \\
\hline \multicolumn{7}{|c|}{ Dosage } \\
\hline & Saline & Low & High & & & \\
\hline Test I nal & & & & & & \\
\hline & 65.4 & 72.2 & 63.6 & $2 / 106$ & 1.57 & n.s. ${ }^{*}$ \\
\hline $\begin{array}{l}\text { Correct Choices (Percentage) } \\
\text { Errors to Criterion }\end{array}$ & $\begin{array}{r}68.5 \\
.51\end{array}$ & $\begin{array}{r}77.2 \\
.51\end{array}$ & $\begin{array}{r}68.5 \\
.69\end{array}$ & $\begin{array}{l}2 / 106 \\
2 / 106\end{array}$ & $\begin{array}{l}2.08 \\
1.13\end{array}$ & $\begin{array}{l}\text { n.s. } \\
\text { n.s. }\end{array}$ \\
\hline \multicolumn{7}{|c|}{ Stimulus Condition } \\
\hline & Normal & Protecte & Stimulate & & & \\
\hline Test Trial & & & & & & \\
\hline Correct Avoidances (Percentage) & 64.2 & 71.0 & 66.0 & $2 / 106$ & .98 & n.s. \\
\hline Correct Choices (Percentage) & 69.1 & 74.7 & 70.4 & $2 / 106$ & 69 & n.s. \\
\hline Errors to Criterion & .56 & .60 & .56 & $2 / 106$ & .07 & n.s. \\
\hline \multicolumn{7}{|c|}{ Interactions: Dosage by Stimulus Condition } \\
\hline \multicolumn{7}{|c|}{ 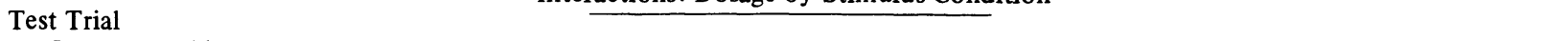 } \\
\hline Correct Avoidances (Percentage) & & & & $4 / 212$ & .27 & n.s. \\
\hline Correct Choices (Percentage) & & & & $4 / 212$ & .77 & n.s. \\
\hline Errors to Criterion & & & & $4 / 212$ & 1.45 & n.s. \\
\hline
\end{tabular}

${ }^{*}$ n.s. $=$ not significant 


\section{DISCUSSION}

The treatment effects that were found in this experiment must be considered in the context of the low level of test trial performance which was found at a delay interval of $5 \mathrm{~min}$. The combined performance of saline-treated animals in the scopolamine $15-\mathrm{min})$ and physostigmine $(5-\mathrm{min})$ conditions was considerably lower than the performance level at similar delay intervals in previous experiments using the same strain and sex of mice (Alpern \& Marriott, 1973; Stripling, 1974) and was only marginally higher than the performance of the salineinjected animals in the physostigmine $(20-\mathrm{min})$ condition. This absence of an STM gradient between 5 and $20 \mathrm{~min}$ is presumably due to a change in procedure from previous experiments. Conceivably, the injection of saline might have aversive qualities which disrupt performance, but previous experiments have administered saline before the sign trial and obtained high levels of performance (Alpern \& Marriott, 1973; Marriott \& Alpern, 1975). However, all previous experiments have treated the animals in an identical fashion every day during the delay interval, while animals in the present experiment were subjected to a different stimulus condition each day. This daily change in the environment during the delay interval may have prevented the animals from habituating to the experimental paradigm, with a resultant disruption of performance. Whatever the cause of the performance decrement, it should be noted that the animals met a very strict criterion of performance during learning set acquisition, and thus were capable of high levels of performance.

The performance decrement did not interfere with the effects of scopolamine. In agreement with previous findings (Alpern \& Marriott, 1973; Marriott, 1974; Marriott \& Alpern, 1975), this drug produced a dose-dependent disruption of STM. The disruptive effect was confined to test trial performance and errors to criterion, the only measures that were interpreted as having an STM component. Sign trial performance was unaffected, indicating that scopolamine had no detectable effect on either the formation or retention of LTM. In addition, no evidence of state-dependent learning with scopolamine was found.

It is important to consider carefully the possible role of nonspecific performance factors in scopolamine's effect on measures of STM. It is clear that motor impairment was not involved, since a highly significant reduction of correct choices on the test trial was produced; an increase in the latency of responding caused by locomotor impairment would not affect this measure. Another possibility is that scopolamine reduced the motivational effect of the footshock. While scopolamine has no analgesic effect (Houser \& Van Hart, 1973), it does increase tissue impedance, thus reducing current intenstiy (Glick, Greenstein, \& Goldfarb, 1973). However, Marriott (1974) found that methscopolamine, which acts peripherally but does not readily cross the blood-brain barrier, had no effect on STM even at a dosage twice as high as the high dosage of scopolamine used in the present experiment. In addition, Alpern and Marriott (unpublished results) found that test trial performance in the present paradigm was unaffected by a sixfold change in the intensity of footshock. Consequently, scopolamine's effect on measures of STM cannot be explained by the alteration of footshock intensity. It appears to act on a central mechanism that is directly involved in STM.

Physostigmine had no effect on measures of STM at a delay interval of either 5 or $20 \mathrm{~min}$. The effects of this drug had not previously been measured by a 5 -min delay interval. Since performance at this interval is normally very good, it was not expected that facilitation beyond this level would occur. Rather it was felt that, if STM were dependent upon cholinergic activity, a physostigmine-produced increase in this activity under conditions at which performance was optimal might cause disruption in a manner analogous to the effects of choli- nesterase inhibitors on retention of LTM observed by Deutsch (1971). The failure to demonstrate such an effect is most probably accounted for by the unusually low level of performance seen in saline-treated animals at this interval compared with similar results reported with this paradigm (see Alpern \& Marriott, 1973). Since 70\%-74? correct choice performance appears to be the test these subjects were capable of in this situation (5-min control data), the detection of a small disruptive action of physostigmine, even if present. would have been precluded. Similarly, a small facilitating action of physostigmine even if present at 20 min could not have been detected.

The continual change of stimulus condition in the present experiment may have been responsible for the poor performance seen at the 5-min delay interval. If true, this indicates the general importance of the environmental situation to the expression of STM. Direct evidence of this importance was obtained by comparing the effect of the three stimulus conditions on STM. The level of sensory stimulation was found to influence STM. but this effect was evident only when animals were treated with scopolamine. Under this drug there was an inverse relationship between the level of sensory stimulation during the delay interval and the strength of STM. The protected condition produced significantly better performance than the normal condition, and there was a trend for the stimulated condition to produce poorer performance than the normal condition.

This is consistent with previous studies of the effects of sensory stimulation on memory. Thompson (1957) found that rats learned a visual pattern discrimination more rapidly if they were placed in the dark for 10 min immediately following each day's training than if they were left in the light. Furthermore, 5 min of darkness had no effect on learning if it was administered $5 \mathrm{~min}$ after the daily training, but produced as much facilitation as $10 \mathrm{~min}$ of darkness if administered immediately after training. Thompson interpreted these results as indicating that normal visual input is disruptive of memory consolidation, but only if present in the period immediately following learning. Calhoun and Murphy (1966) found that subsequent retention in mice of one-trial passive avoidance learning was facilitated by placement in a dark sound-deadened chamber for the 30 -min period immediately following training but that visual, auditory, and kinesthetic stimulation during this time produced no disruption in comparison to animals which were exposed to normal levels of environmental stimulation.

Both of these experiments indicate that normal levels of sensory input in the period immediately following a learning event have a disruptive effect on subsequent retention of that event. While retention in the learning paradigms of both these experiments measured LTM rather than STM, it is possible that the effects of sensory stimulation were on STM if the strength of LTM is affected by alterations in STM. This interpretation is supported by the finding of Thompson (1957) that a reduction in visual input affected retention only if it was made within 5 min of training.

Neither Calhoun and Murphy (1966) nor the present experiment found a disruptive effect of increasing the environmental stimulation beyond that present under normal conditions, although the present experiment found a trend in that direction. This suggests that the disruptive effect of normal levels of stimulation is relatively large and difficult to exceed. This may be particularly true of the present experiment, since animals in the normal condition were exposed not only to irrelevant sensory input but also could hear the $1 / 2-$ sec warning tone whenever another animal was being given a trial in the T-maze.

The finding that changes in sensory stimulation affected STM only under scopolamine suggests that both these variables act on the same mechanism. Other research supports this suggestion. Warburton and Brown (1971) analyzed the effects of scopolamine on operant behavior controlled by a discriminative stimulus in terms of signal detection theory and found that the drug's primary effect was to reduce the signal-to-noise 
ratio. This finding implies that the effect of scopolamine on sensory input is related to attentional processes, since the discrimination between relevant stimuli and other input was impaired. Warburton (1972) interpreted these and other results as indicating that a cholinergic mechanism mediated the Pavlovian concept of internal inhibition by inhibiting the effects of irrelevant on nonreinforced stimuli. A similar formulation to this but couched in terms of habituation was made by Carlton (1968).

A formulation such as this which distinguishes between relevant and irrelevant stimuli can account for the results found in the present experiment. If the sensory input which occurs during the sign trial and which is the basis for performance on the test trial is considered "relevant" and the sensory input which occurs during the delay interval is considered "irrelevant," then the results can be stated in the following terms. Under conditions where cholinergic activity was normal or high (saline or physostigmine), relevant stimuli were adequately processed, as indicated by the relatively high level of test trial performance, and irrelevant stimuli were inhibited to the extent that they did not significantly interfere with the processing of relevant stimuli, as indicated by the absence of an effect of sensory stimulation on STM. Under conditions where cholinergic activity was low (scopolamine), relevant stimuli were not as adequately processed, as indicated by the low level of test trial performance, and irrelevant stimuli had a disruptive effect on the processing of relevant stimuli, as indicated by the impairment of STM by sensory stimulation during the delay interval.

Thus, the data of the present experiment suggest that the expression of STM is strongly influenced by a cholinergic mechanism that modulates the selectivity of sensory processing. This mechanism would presumably act by facilitating the shortterm storage of input which is perceived as being of significance to the organism, perhaps through some form of neural rehearsal. Input perceived to be without significance to the organism would be suppressed so as not to compete with the storage of relevant information.

\section{REFERENCES}

Alpern, H. P., \& Marriott, J. G. A direct measure of short-term memory in mice utilizing a successive reversal learning set. Behavioral Biology, 1972, 7, 723-732. (a)

Alpern, H. P., \& Marriott, J. G. An analysis of short-term memory and conceptual behavior in three inbred strains of mice. Behavioral Biology, 1972, 7, 543-551. (b)

Alpern, H. P., \& Marriotr, J. G. Short-term memory: Facilitation and disruption with cholinergic agents. Physiology and Behavior, 1973, 11, 571-575.

Calmoun, W. H. Effect of level of external stimulation on rate of learning and interaction of this effect with strychnine treatment in mice. Psychological Reports, 1966, 18, 715-722.

Calhoun, W. H., \& MurPhy, R. J. Pre- and post-trial stimulation: Effects on retention. Psychonomic Science, 1966, 5, 435-436.
Carlton, P. L. Brain acetylcholine and habituation. In P. B. Bradley and M. Fink (Eds.), Progress in brais research: Vol. 28. Anticholinergic drugs and brain functions in animals and man. Amsterdam: Elsevier, 1968.

DeEse, J., \& Hulse, S. The psychology of learning. New York: McGraw-Hill, 1967.

Deutsch, J. A. The cholinergic synapse and the site of memory. Science, 1971, 174, 788-794.

Essman, W. Drug effects and learning and memory processes. Advances in Pharmacology and Chemotherapy, 1971. 9, 241-330.

Glick, S. D., Greenstein, S., \& Goldfarb, J. Increased electrical impedance of mice following administration of scopolamine. Behavioral Biology, 1973, 9, 771-775.

Glickman, S. E. Perseverative neural processes and consolidation of the memory trace. Psychological Bulletin. 1961, 58. 218-233.

GREEN, E. (ED.) Biology of the laboratory mouse. New York: McGraw-Hill, 1966.

Heвs, D. O. The organization of behavior. New York: Wiley, 1949.

Houser, V. P., \& VAN HART, D. A. The effects of scopolamine and pilocarpine upon the aversive threshold of the rat. Pharmacological and Biochemical Behavior. 1973, 1. 427-431.

MARRIOTt, J. G. Adrenergic and cholinergic drug effects upon short-term memory in mice. Unpublished doctoral dissertation, University of Colorado, 1974.

Marriott, J. G., \& Alpern, H. P. Adrenergic and cholinergic drug effects upon short-term memory in mice. Submitted for publication, 1975 .

McGaugh, J. L., \& Herz, M. Memory consolidation. San Francisco: Albion, 1972.

RunYon, R., \& HABER, A. Fundamentals of behavioral statistics. Reading, Mass: Addison-Wesley, 1971.

Stripling, J. S. Genetic, biochemical, and environmental variables in the expression of short-term memory in the mouse. Unpublished doctoral dissertation, University of Colorado, 1974.

Tномpson, R. Retroactive effect of interpolated visual stimulation. Psychological Reports, 1957, 3, 183-188.

Thompson, R., \& Bryant, J. H. Memory as affected by activity of the relevant receptor. Psychological Reports, 1955, 1, 393-400.

WarbuRTon, D. M. The cholinergic control of internal inhibition. In R. A. Boakes and M. S. Halliday (Eds.), Inhibition and learning. London: Academic Press. 1972.

W ARBURTON. D. M., \& Brown, K. Attenuation of stimulus intensity induced by scopolamine. Nature, 1971, 230, 126-127.

(Received for publication May 8, 1975; revision received July 31,1975 ; accepted August 11, 1975.) 